\title{
Pros

\section{EL ENGAÑO DE LA PIEL: LA TRANSMUTACIÓN ALQUÍMICA DEL SUJETO TRANSEXUAL EN LA PIEL QUE HABITO}

\author{
THE ART OF DECEIT: THE ALCHEMICAL MAKEOVER OF THE TRANS- \\ SEXUAL SUBJECT IN LA PIEL QUE HABITO \\ Antonia L. Delgado-Poust \\ University of Mary Washington \\ adelgado@umw.edu
}

RESUMEN: El presente artículo considera el proceso creativo y transformativo por el que pasa el/la protagonista transexual de La piel que habito (2011) y lo equipara al proceso antiguo de la alquimia, pues ambos tienen como objetivo el perfeccionamiento, la imitación y la adulteración, o falsificación, de la naturaleza. El propósito principal del ensayo, aparte de delinear los elementos alquímicos presentes en el filme, es explorar la (con)fusión de ciertos binarios, como lo auténtico y lo artificial, lo masculino y lo femenino y el Yo y el Otro. Se plantea que, como en la alquimia, Almodóvar presenta a la figura del transexual -o del hermafrodita-como el ser perfecto, o la Piedra Filosofal, ya que encarna tanto lo femenino como lo masculino en un solo cuerpo. Además, a semejanza del oro alquímico y de las obras de arte, se propone que el/la protagonista, Vicente/Vera, representa una copia más perfecta de su referente original, lo cual subraya su nebulosa autenticidad existencial. Al final de este estudio, se establece un vínculo entre la transformación física y ontológica de Vicente/Vera y la mise-en-scène que este realiza para poder sobrevivir. Se concluye que el carácter transformativo e ilusorio de lo teatral concuerda con el aspecto experimental y artificioso de la alquimia.

Palabras ClaVe: Almodóvar, alquimia, autenticidad, engaño, perfección, transformación, transexualidad

ABSTRACT: This article considers the creative and transformative process undergone by the main protagonist -a transsexual- of La piel que habito (2011) while comparing it to the age-old alchemical process, as the two share a common objective: the perfection, imitation, and adulteration-or falsification-of nature. The main purpose of this essay, aside from delineating the alchemical motifs present throughout the film, is to explore the (con)fusion of a particular set of binaries, 
such as the authentic and the artificial, the masculine and the feminine, and the Self and the Other. The author maintains that, as with alchemy, Almodóvar presents the figure of the transsexual, or of the hermaphrodite, as the perfect being, or the Philosopher's Stone, as s/he embodies both the feminine and the masculine in one body. Moreover, like alchemical gold and works of art, this study proposes that the protagonist, Vicente/Vera, represents a more perfect copy of the original, which underscores his/her ambivalent existential authenticity. The author highlights the similarities between Vicente/Vera's physical and ontological transmutation and the mise-en-scène in which he/she must embark in order to survive. Finally, the essay concludes that the transformative, illusory nature of the theatrical parallels the experimental and deceiving aspect of alchemy.

Keywords: Almodóvar, Alchemy, Authenticity, Deceit, Perfection, Transformation, Transsexuality

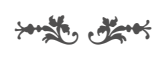

Desde el estreno de Laberinto de pasiones en 1982, la obra cinematográfica de Pedro Almodóvar se ha caracterizado tanto por la metamorfosis física como por la esencia híbrida, ambigua y performativa de sus personajes, los cuales representan un desafío a la supuesta distinción entre lo auténtico y lo artificial, o lo masculino y lo femenino. Además, los cuerpos e identidades de dichos protagonistas están sometidos a una serie de transformaciones, arreglos, amputaciones y sustituciones, que, según Jean-Max Méjean (2007), suelen ocurrir en un entorno clínico que recuerda el laboratorio del alquimista antiguo. En La piel que habito (2011), el cineasta manchego retoma los temas de la mutación, del arreglo y del ambiente clínico para presentarnos de nuevo al sujeto transexual trasfigurado. No obstante, dicha metamorfosis física y existencial es siniestra y engañosa, debido en parte a que se hace sin el permiso de la figura trocada y a que el cuerpo transformado funciona como un trompe d'oeil que engaña al espectador desde el primer momento en que aparece en pantalla. En vez de emplear el hospital -un espacio público intensamente controlado- como el lugar de la transformación, Almodóvar decide que será en la casa del cirujano y en su quirófano privado donde se lleve a cabo el proceso evolutivo, lo cual resalta el carácter íntimo, clandestino y perverso de la transformación corporal.

En el presente ensayo me propongo explorar las cuestiones de identidad, de género y del cuerpo humano en La piel que habito como entidades que se conciben y que están sujetas a un proceso transformativo, análogo a la metamorfosis alquímica. A mi modo de ver, en este filme Almodóvar evoca una serie de metáforas asociadas con la alquimia para resaltar los procesos de creación, defunción, transformación, "purificación" o perfeccionamiento, a los que está sometido el/la protagonista por un médico sin escrúpulos, cuyo fin es el de forjar a la mujer ideal, envuelta en la piel perfecta. Como se verá a continuación, el 
derivado alquímico, personificado en el filme por un ser bigenérico o transexual, no solo pone en tela de juicio una vez más la existencia de los imaginados límites entre la autenticidad y la imitación, sino que cuestiona también lo que separa al hombre de la mujer, el animal -o máquina- del ser humano, y, por tanto, el "Yo" del "Otro". Huelga decir que la alquimia almodovariana que se plantea en este ensayo va mucho más allá de la fabricación de oro artificial, pues al mismo tiempo que transforma los metales, Almodóvar presenta el cuerpo humano como el locus de la transformación alquímica. A mi modo de ver, el cambio físico y químico por el que pasa el/la paciente es engañoso, ya que, como el oro alquímico, dicho cambio no es más que una imitación o espejismo de la naturaleza. La imposibilidad de distinguir entre lo auténtico y lo fabricado en el filme trae a colación los profundos dilemas éticos asociados con la obsesiva búsqueda de la perfección y del control sobre la naturaleza.

Como ha destacado Xavier Aldana Reyes en su estudio "Skin Deep", La piel que habito subraya la amenaza inminente de (los abusos de) la ciencia a la vez que dialoga con la tradición cinematográfica del horror quirúrgico y la tortura pornográfica (2013: 820). Efectivamente, basada en la novela de suspense Mygale (Jonquet 1984) y con vestigios de las inquietantes películas Les yeux sans visage (Franju 1960) y Metrópolis (Lang 1927), La piel que habito es a la vez la historia de un creador-genio y su obra y la de una venganza espeluznante y destructora que resulta en la transmutación de género de un ser humano en contra de su voluntad. Robert Ledgard -amalgama postmoderna del Doctor Génessier, Hermes/Volcán, Pigmalión y el mismo Frankenstein, entre otros- es un cirujano plástico ilustre que se ha dedicado obsesiva y secretamente a la creación de una nueva piel tras la muerte de su esposa, Gal, la cual sufrió quemaduras en todo el cuerpo en un accidente de tráfico. ${ }^{1}$ El cirujano se comporta como un adepto de la alquimia y un científico loco, ya que aspira a la eterna juventud, a ser creador de una obra maestra -su propia Galatea- y a trasgredir los límites científicos y éticos establecidos que le impiden avanzar libremente con sus proyectos arriesgados. En Body Gothic (2014), Aldana Reyes ha señalado que ya que el científico, debido a su pasado alquímico, se asocia con la magia y con la capacidad de hacer posible lo imposible, es a través de la llamada ciencia loca o "mad science" que se pueden explorar los límites del cuerpo y de la existencia humana (2014: 147). En cierto modo, se podría alegar que el Doctor Ledgard se dedica a esta ciencia loca, ya que doce años después de fallecer su esposa, el cirujano consigue lo imposible: cultivar una nueva piel ignífuga en su laboratorio: "una piel sensible a las caricias, pero una auténtica coraza contra todas las agresiones, tanto externas como internas" (Almodóvar "Sinopsis" 2011). Para llevar a cabo esta tarea, y siempre a espaldas del presidente del Instituto de Biotecnología de Madrid, el cirujano utiliza un procedimiento conocido como la "transgénesis", la cual transfiere la información genética de una célula porcina a una célula humana, en este caso a la de su último conejillo de Indias, Vera Cruz. Mediante la analepsis, Almo-

\footnotetext{
1 Véase el análisis de Yvonne Gavela-Ramos, "La piel que habita el cine de Almodóvar", que considera, entre otros temas, el proceso de creación artística que se desarrolla en la representación y el desmantelamiento del mito de Pigmalión y Galatea en La piel que habito.
} 
dóvar nos va revelando ciertos detalles sobre la identidad de este personaje tan enigmático, el cual se llamaba Vicente Guillén Piñeiro antes de conocer a Ledgard y que ahora convive con él en contra de su voluntad durante seis años. En su vida anterior, Vicente era un joven costurero, que, al parecer, violó a Norma, la hija del cirujano, en la fiesta de una boda. Pronto nos damos cuenta de que el cambio de sexo que Ledgard le hace a Vicente es, más que nada, un castigo por el presunto crimen cometido. Al mismo tiempo, este proyecto vengativo hace que el violador se ponga literalmente en la piel de una mujer, imagen usada en castellano para ver el punto de vista o la experiencia de otro.

\section{LA TRANSFORMACIÓN PURIFICADORA ALQUÍMICA Y LA BÚSQUEDA DE LA PERFECCIÓN} O LA INMORTALIDAD

De esta forma, Almodóvar nos recuerda en el largometraje que la identidad, el género y el cuerpo humano, a semejanza de los metales vulgares empleados en los experimentos alquímicos, no son entidades fijas, sino que están sujetas a la interpretación y a un proceso paulatino, sea en forma de desarrollo y crecimiento o como una especie de deterioro orgánico que, tras pasar por un proceso de purificación o redención, se convierten en su forma más perfecta. Como bien recalca Alfredo Martínez-Expósito, el cuerpo es para Almodóvar un lugar privilegiado de acontecimientos, "un escenario [...] donde la narración cobra todo su sentido, y por ello no es de extrañar ese interés suyo por un género que hace de la mutilación, la disección y el dolor real o temido el centro del desarrollo narrativo" (2004: 196). En películas como ¡Átame! (1990), Todo sobre mi madre (1999), La mala educación (2004), y ahora en La piel que habito, el cineasta destaca la maleabilidad, artificialidad y fluidez del cuerpo y de la identidad humana. Es más, en su análisis de la obra almodovariana, Steven Marsh explica que

... throughout Almodóvar's oeuvre, bodily metamorphosis plays a central role, as is evident in the many depictions of organ transplants, sex changes, testtube babies, cyborgs, and plastic surgery. Bringing fluid conceptions of bodily identity into play with more fixed conceptions of the body in medical discourse and practice, Almodóvar grapples with the possibilities and limits of transforming, remaking, or restyling the human. (Marsch 2009: 339)

Partiendo de las observaciones de Martínez-Expósito y Marsh, podemos decir que las metáforas de la mutabilidad y la transformación física, emocional y existencial, así como del sufrimiento y el perfeccionamiento del ser humano que están presentes en casi toda la obra almodovariana y en La piel que habito, en particular, están estrechamente relacionadas con el proceso alquímico. Es más, la antigua práctica protocientífica y disciplina filosófica de la alquimia, arraigadas en la combinación de disciplinas como la química, la metalurgia, la medicina, y el arte, son fundamentales para apreciar mejor el proceso transformativo por el que pasa la figura transexual del filme.

A todas luces, el cineasta subraya que la actual preocupación por la perfección y la purificación físicas o espirituales, así como el afán de conseguir la 
eterna juventud o la inmortalidad, son análogos a los empeños protocientíficos de los alquimistas antiguos que iban en busca de la anhelada piedra filosofal. De acuerdo con Gebelein, el alquimista intenta elaborar la piedra filosofal mediante la aplicación del fuego, el cual transforma los metales innobles en el preciado oro, el metal "perfecto" por excelencia, debido a su constancia y resistencia a la combustión (Gebelein 2007: 38). Se considera que la piedra filosofal, la cual actúa sobre los minerales, o el elixir de la vida, elemento purificador de los cuerpos, simboliza el logro de la integridad y funciona como un remedio maravilloso que puede curar el cuerpo humano de enfermedades, posponer la vejez y, por tanto, alargar la vida de manera indefinida. En la película, son las células porcinas las que, una vez mezcladas con las de ser humano para formar una nueva piel ignífuga y resistente a los efectos del paso del tiempo, se convierten en el codiciado elixir alquímico. Como ha señalado Esteban Rodríguez Ocaña, este hecho se debe a que, tras la dominación de los metales, el adepto alquímico se convierte en un demiurgo o "señor del fuego que [puede] redimir la materia y perfeccionar lo existente" (1991: 7) mediante lo que M. E. Warlick considera que es un proceso "de trabajo persistente y de cambio constante que lleva a la purificación y refinamiento del cuerpo" (2003: 9). En vez de transformar los metales básicos en oro, el cirujano plástico del largometraje, a semejanza del alquimista o artista, manipula lo imperfecto, indeseado o caído y lo convierte en una obra maestra por medio de la transgénesis y su experimentación con el fuego. No obstante, el lienzo, los "metales" o elementos básicos con los que experimenta este personaje son la piel y la identidad humanas. Ledgard se compromete durante años a descubrir una nueva panacea y, tras un arduo proceso de prueba y error, llega a desarrollar una piel perfecta, ignífuga y eterna, su piedra filosofal. En su laboratorio clandestino y subterráneo del caserón toledano El Cigarral, el cirujano, al igual que un alquimista postmoderno que tiene que ocultar sus conocimientos al mundo exterior, y de manera especial a sus colegas del Instituto de Biotecnología, se rodea de pipetas, placas de Petri, muestras de sangre y subterfugios que le sirven para llevar a cabo sus experimentos más espantosos. ${ }^{2}$

Cabe recordar que el afán de los alquimistas antiguos por convertir cualquier metal en oro era, en gran medida, simbólico. Por consiguiente, la alquimia también indaga en cuestiones tales como la constitución esotérica y la mejora o renacimiento no solo de una cosa, sino también del mismo adepto, por medio de una aplicación de los misterios del nacimiento, muerte, purificación o resurrección. ${ }^{3}$ Al ubicar la trama del filme en una finca señorial cuyo nombre deriva de cigarra, a causa de la abundancia de estos insectos y "su incansable

\footnotetext{
2 Como sostiene Jean-Max Méjean, el entorno hospitalario es "un lugar de transformaciones, de implantes, hasta de un salón de belleza" que recuerda el laboratorio del alquimista antiguo, e incluso del Doctor Frankenstein, puesto que tanto el hospital como el laboratorio clandestino del adepto son espacios en los que las sustancias y los cuerpos humanos son parcelados, "complementados, sustituidos, incluso modificados o transformados" (2007: 69).

${ }^{3}$ El anhelo de transformar metales en oro o de mejorar cualquier cualidad humana considerada inferior recuerda el concepto cristiano de la resucitación y la redención de los muertos pecadores (Schwartz-Salant 2003: 10).
} 
coro en las calurosas jornadas del verano" (Marañón y Bertrán de Lis 2015: 19), Almodóvar trata de resaltar los temas de la mutabilidad, la metamorfosis y la identidad, tan representativos de su obra artística. Como la mayoría de los insectos, la cigarra cambia, o muda, de "piel" y, al emerger de la tierra, abandona su antigua membrana antes de que la "segunda" piel se endurezca para convertirse en adulto. Como se verá más adelante, la figura de la cigarra le sirve al director manchego de metáfora de la transmutación de su protagonista, Vera, la cual padece un tipo de destrucción y defunción. No obstante, a semejanza del ave Fénix, logra sobrevivir y, con el cambio de piel y de cuerpo renace y se vuelve inmortal. Además, de acuerdo con los antiguos alquimistas, son los símbolos básicos de la serpiente pulverizada y la salamandra los que encarnan a la perfección el carácter ignífugo de la piedra filosofal, además de los conceptos de metamorfosis, adaptación, palingenesia, renovación cíclica y purificación. Por otra parte, en las representaciones heráldicas modernas, aunque la salamandra parece estar envuelta en llamas nunca se quema, ya que, según muchos alquimistas, esta consumía el fuego y podía templarlo con su piel fresca e impenetrable. A semejanza de la salamandra y del elixir, la nueva piel de Vera es capaz de resistir las quemaduras literales y figurativas que Ledgard le aplica, mientras que, como el Fénix, el uróboros, también resucita al final del filme de sus propias "cenizas", aprende a adaptarse a su nueva existencia, y renace a la libertad.

El motivo del fuego al que ya he aludido se repite a lo largo de La piel que habito y sirve para resaltar los conceptos más emblemáticos de la obra almodovariana, como son la destrucción/putrefacción, la reencarnación/transformación y la purificación del sujeto alquímico y transexual, y la del mismo adepto que lleva a cabo el experimento. Según señala Paracelso, la alquimia no es más que un arte que convierte lo impuro en puro mediante el fuego (Jacobi 1995: 143). En el caso particular de Vicente/Vera, la impureza se vincula a su supuesto delito-la violación de Norma, la única hija de Ledgard. ${ }^{4}$ Por su parte, Bettina Knapp ha indicado que el fuego representa el deseo o la búsqueda ardiente de una evolución espiritual e intelectual, transformándose de esa forma en un instrumento de regeneración y purificación (1980: 160). En el filme, la ciencia avanza gracias a la elaboración subrepticia de Vera y la nueva piel ignífuga con que la encubre Ledgard. De esa forma recupera a su esposa muerta, ya que su nueva criatura parece ser una reencarnación o simulacro de la difunta, puesto que las dos comparten muchos de los mismos rasgos físicos. De hecho, Gal muere a causa de un incendio y gracias a este accidente Ledgard no solo logra crear una piel más sofisticada y noble que la original a través de Vera, sino que al mismo tiempo se redime y se regenera a sí mismo en el ámbito profesional y personal. Además, como se verá más adelante, es por medio del castigo -del cambio de

\footnotetext{
4 Teofrasto Paracelso, un filósofo alquimista y médico suizo del siglo dieciséis, creía que había conseguido que el plomo se convirtiera en oro. Fue una figura interesante y controvertida de la historia de la medicina, puesto que iba en busca de lo moderno, siempre oponiéndose a la tradición. A semejanza del Doctor Frankenstein, Pigmalión y el Doctor Génessier, a Ledgard también se le podría comparar con el inusual médico suizo. Está convencido de que ha descubierto o creado una piel perfecta y está dispuesto a hacer todo lo que se considere necesario para que su invención tenga éxito, incluso si tiene que desobedecer las reglas establecidas.
} 
sexo obligado que le hace a Vicente- que Ledgard absuelve, o "purifica", no solo a su víctima, el agresor de su hija, sino también a su difunta esposa, la cual le fue infiel antes de morir.

Como símbolo de la reencarnación de Gal y a semejanza del ave que se viste de plumas nuevas después de mudar de piel, Vera logra deshacerse de "impurezas" y renovar así el cuerpo antiguo de Vicente y el de Gal. Siguiendo con la imagen del fuego y con una de las etapas más trascendentales del proceso alquímico -que se denomina el albedo-Vera, como el ave Fénix, encarna lo que no solo emerge o renace de la ceniza de lo aniquilado o muerto, sino también de lo que ya no se puede quemar, alterar o destruir más, personificando en consecuencia lo físicamente bello, lo purificado y lo inmortal. Asimismo, he de señalar que el fuego, tanto en la alquimia como en la película misma, suele poseer poderes curativos y regenerativos, incluso después de los traumas y tragedias. Después de la violación de Vera aparecen Vera y Marilia (la madre biológica de Ledgard, sin que él lo sepa) frente a una hoguera, cuyas llamas queman, aniquilan y purifican tanto el edredón manchado de sangre sobre el que fue violada la protagonista como a esta misma.

\section{La elaboración alquímica de la mujer "perfecta" o "AuténticA"}

A lo largo de los siglos, los adeptos que han llevado a cabo el proceso alquímico se han enfrentado al dilema moral que entraña la manipulación de la naturaleza. Según varios textos alegóricos antiguos en los que se trata dicho proceso, el segundo objetivo principal de la alquimia es la creación de la vida o la reproducción artificial del hombre mediante la manipulación de los tejidos orgánicos humanos y animales. ${ }^{5}$ En el caso del Doctor Ledgard, el afán de manipular la naturaleza y de descubrir una nueva panacea con la elaboración de la piel sintética lo lleva no solo a crear una vida, sino también a destruirla. A semejanza del Doctor Frankenstein, el cirujano abusa de su papel como científico al intentar jugar a Dios. Como el mismo Pigmalión, a medida que Ledgard va perfilando la construcción de su obra, la erotiza hasta tal punto que le resulta casi imposible no enamorarse de ella. La piel que habito, a semejanza de La ley del deseo (1987), Todo sobre mi madre, La mala educación y otras obras anteriores del director, se centra en la idea de que la identidad y el cuerpo femeninos son representaciones y construcciones concebidas y -en el caso de este largometraje- llevadas a cabo por un hombre que proyecta en ellos sus deseos más rencorosos y arraigados en los ideales tradicionales de la feminidad. Aunque la protagonista de La piel que habito no ha escogido el cuerpo o el género que le han sido impuestos, estos han sido elaborados y manipulados de manera escrupulosa por y para el deleite de su autor. Mediante la imagen del maniquí, Almodóvar enfatiza el subsiguiente

\footnotetext{
${ }^{5}$ A dicha reproducción híbrida del ser humano se le denomina "homúnculo" ("hombre pequeño"), una criatura creada, supuestamente por el mismo Paracelso, cuya función era proteger a su inventor. Curiosamente, poco después de su elaboración, el homúnculo se volvía contra su creador y huía, lo cual recuerda el caso del monstruo de Frankenstein y, como se verá más adelante, el de la misma Vera.
} 
forjamiento y cosificación de Vera, la cual será tratada como si fuera la presa o muñeca personal de su creador, que, tal y como reconoce ella misma, "[está] hecha a [su] medida", como una Galatea postmoderna. Gracias a los conocidos trabajos de Foucault, Butler y de Beauvoir, entre otros, en la actualidad se habla del género como de una entidad construida, producto de un proceso consciente en vez de como una verdad coherente, íntegra y biológica. De esta forma, después de que el cirujano le hace una serie de arreglos a la paciente, esta le pregunta si se la puede considerar como "acabada", a lo que él replica que todavía no. Esto insinúa que, según Ledgard, Vicente/Vera aún no encarna el ideal ni la "autenticidad" femeninos y que el cuerpo y la esencia femeninos son el resultado de un proceso paulatino y doloroso de experimentación intensa y perversa, es decir, el azar, y una tortura sistemática llevada a cabo por un cirujano obsesionado con la venganza y la perfección epidérmica y femenina. En su afán de construir la obra y el cuerpo femenino perfectos, Ledgard se encarga de feminizar y de hacerle (la piel) incorruptible, o inmortal, a Vicente/Vera. Mientras que la feminización forzada del cuerpo masculino simboliza el logro de la perfección estética, también representa el castigo y la humillación del "pecador". Para Ledgard, este castigo y humillación consisten en impedir que el violador vuelva a pecar, o, dicho de otra forma, que vuelva a experimentar el placer o el poder sexual de los que disfrutaba antes como hombre heterosexual.

El cirujano no solo ha secuestrado al paciente contra su voluntad, sino que también lo ha remodelado, cambiándolo para siempre, tras una serie de procedimientos quirúrgicos profundos y difícilmente reversibles, como el trasplante de rostro, la castración, la vaginoplastia, la hipoplasia mamaria y los xenotrasplantes. Estos últimos suponen el trasplante de células, tejidos u órganos de una especie a otra, como de cerdos a humanos, en el caso específico de la protagonista. Por lo tanto, a raíz de estas operaciones "purificadoras", Vicente/Vera no solo no es el/la mismo/a de antes, sino que, por el contrario, está compuesto/a de partes foráneas y tal vez incompatibles con su cuerpo e identidad anteriores. Cuando Vicente descubre lo que Ledgard le ha hecho, queda horrorizado y se ve obligado a aceptar su nueva identidad, al menos en presencia del cirujano. Cuando está recuperándose después de la primera fase de operaciones, Vicente, evidentemente más feminizado que antes, se mira en el espejo y duda de si debe comprobar por debajo de la bata el nuevo orificio, o vacío, que se le ha asignado. Como se ve en el modelo lacaniano ("Le Stade du miroir" 1949: 449-455), el espejo le revela a Vicente un cuerpo con el que no se identifica. Es decir, al inspeccionar el reflejo de su imagen, Vicente vislumbra al Otro, o a la Otra, quien, tras una serie de procedimientos más, pronto se convertirá en Vera. Después de contemplarse en el espejo, entra Ledgard en la habitación y le advierte a su paciente que es muy importante mantener abierto su nuevo orificio y hacerlo más profundo, al mismo tiempo que insiste en que su vida depende de ese agujero y que es necesario que respire por él. Aquí, Ledgard le recuerda a Vicente que es creación y posesión suya y que la única manera de que sobreviva es asumir su nueva piel y su identidad sexual indeseadas. ${ }^{6}$

6 Siguiendo de nuevo a Lacan ("La signification du phallus" 1958) y a Freud (Teorías sexuales 
No es casual que Almodóvar haya escogido la alquimia para subrayar el conflicto entre el arte y la naturaleza y la tensión entre lo auténtico y lo inauténtico. La alquimia, como el arte y la belleza, aspira a la autenticidad y a la perfección. No obstante, de acuerdo con la filosofía de Platón, tanto el arte como la perfección y la belleza no son más que meras imitaciones de la "verdad" que fomentan el engaño visual (Azara 1995: 35-36). De manera análoga, en su crítica del oro alquímico, el erudito musulmán Averroes señala que, aunque una reproducción engendrada por mediación humana se asemeje perfectamente al ejemplo original, engendrado por medios "naturales", la artificial nunca será genuina, sino falsa (Newman 2005: 6). En cambio, para el cirujano, Vera llega a encarnar finalmente no solo la perfección, sino también, paradójicamente, la autenticidad femenina, pero solo cuando Ledgard la da por terminada. ${ }^{7}$ Pese a esto, dicha autenticidad es, por naturaleza, engañosa, puesto que se basa en la imitación o reproducción del referente original: Gal. Como él mismo le anuncia, jactándose mientras inspecciona los frutos de su labor, sus senos ya no parecen tan "neumáticos" (es decir, mecánicos o artificiales) como antes, sino como "gotas de agua que resbalan sobre la superficie de un cristal". Para Ledgard, dichos senos, como la piel artificial que envuelve a su paciente, son la sinécdoque de su cuerpo entero, y tal vez hasta de su nueva identidad. A su modo de ver, son aún más verosímiles, delicados y "naturales" que los originales. A pesar de que el espectador sabe que Vera es un simulacro o una reproducción de la verdad, también se percata de lo difícil -o casi imposible- que es distinguir el artificio de la realidad, debido en parte a que la actriz que interpreta el papel de Vera -Elena Anaya, a semejanza de Carmen Maura en La ley del deseo- no solo se identifica como mujer y lesbiana en la vida real, sino que en el filme hace de transexual que imita a una mujer heterosexual, pero a la que le atraen las mujeres, lo cual añade otra capa más al carácter ambiguo y artificioso de la protagonista. En su análisis de La ley del deseo, Isolina Ballesteros señala que la figura de Tina "ejemplifica [...] la desconstrucción de la oposición 'construida' versus 'esencial' que el transexualismo representa" (2001: 121), mientras que Adriana Virginia Bonatto subraya que Tina encarna lo que tradicionalmente se denominaría "falso" o inauténtico (2017: 1478). Queda claro que esta caracterización almodovariana de los

infantiles 1908), el caso de la castración, que para Vicente es literal, representa la pérdida del Yo. Según esta teoría, sin el falo y, en consecuencia, el sexo masculino, Vicente también ha cambiado de identidad, convirtiéndose en (el) o/Otro. Al amputar el órgano con el que Vicente ha violado a su hija, Ledgard siente que redime a Norma, a la vez que castiga y purifica a su agresor, impidiendo que vuelva a cometer un crimen semejante. Asimismo, el cirujano le usurpa todo el poder y el placer de los que antes gozaba gracias a su género masculino y, a su modo de ver, lo convierte en un ser indefenso y pasivo; es decir, en una mujer.

7 No es casualidad que, como destaca Carl G. Jung, en la mitología romana Venus fuera la esposa de Volcán, el dios del fuego, la alquimia y los metales (1953: 384). Es más, como señala GavelaRamos, en varias escenas de la película, Vera adopta la misma postura de las dos Venus de Tiziano que cuelgan de las paredes principales del caserón (2013: 118). A semejanza de la diosa romana en este cuadro, Vera encarna los conceptos alquímicos de la transformación y el (re)nacimiento tanto como de la muerte. A través de estas correspondencias, Almodóvar resalta que Vera personifica la figura tradicional de la musa o mujer-objeto de deseo y de la creación plástica, producto de la imaginación masculina. 
personajes "trans" se mantiene constante en La piel que habito, ya que lo mismo se podría decir de Vera. Es más, los retoques que le hace el cineasta a la piel de Anaya después del rodaje la hacen parecer aún más perfecta y, por ende, más artificial de lo que es. Aquí vemos cómo, una vez más, Almodóvar nos obliga a cuestionar lo que se quiere decir con "auténtico", "natural" o "perfecto", a la vez que nos reta a no fiarnos del todo de las apariencias.

Si consideramos que el caserón y la habitación de Vera son espacios herméticos, semejantes al alambique empleado en la alquimia, la llegada de Zeca a El Cigarral sirve como un catalizador que incita un cambio fundamental en la transformación de las sustancias manipuladas (Vera). En una de las escenas más polémicas de la película, Zeca -el medio hermano de Ledgard-vestido de tigre para el Carnaval y para ocultar su identidad, entra por la fuerza en el custodiado caserón y viola a Vera. Según los aforismos herméticos, las relaciones sexuales (sean consentidas o no) son similares a la transformación alquímica, puesto que en dichos encuentros íntimos se intercambian los fluidos corporales y se unen y se vuelven a separar los cuerpos, guiados por las mismas leyes de atracción y repulsión que rigen las sustancias materiales. Además, es donde se establece el equilibrio entre dos elementos opuestos en conflicto mutuo -el coniunctio del proceso alquímico- y donde existe un tipo de transmutación de cuerpos y almas. Huelga decir que el encuentro sexual entre Zeca y Vera no es placentero ni beneficioso en absoluto para la víctima, pero, a semejanza de la violación de Hable con ella (2002), sí funciona como una especie de catalizador para una transformación más para la protagonista, además de un cambio en la relación entre el cirujano-genio y su presa-musa. En esta escena, que recuerda el momento en que Volcán -el dios forjador- descubre a su esposa Venus en el lecho con Marte y a la vez en que el propio Ledgard descubre a Gal con Zeca, el cirujano halla a su paciente en la cama con el hombre-tigre, confundiendo la violación con un acto consensuado, y finalmente mata a la bestia con su pistola. No obstante, Vera yace en lo que parece ser la sangre de su violador, ya que acaba de ser violada. Esta sangre también se ha comunicado y mezclado con la suya, confundiendo una vez más a la víctima con su violador. Las manchas que ahora tiñen la colcha de rojo no solo indican la defunción (el nigredo) de uno, sino que también sirven como metáfora de la menstruación y, por ende, de la vida o el renacimiento en otra forma, lo que en el proceso alquímico se designa como el albedo. A semejanza del símbolo de la prisión, la cama también puede representar el huevo filosofal, y es precisamente en este lecho donde se lleva a cabo una transformación existencial importante. Vicente, el violador de Norma, se ha transformado en el Otro (o en la Otra), en el cuerpo extraño y femenino, cuyas funciones principales son satisfacer el placer sexual y, al mismo tiempo, ser observada, deseada y dominada por el sujeto masculino. Tras la violación, para Ledgard, Vicente se convierte simbólicamente en una mujer redimida, pues es precisamente después de esta transgresión que Ledgard quiere llevarla a la cama y convertirla en su amante. Además, considerando que para Almodóvar el color rojo se asocia con la sangre, la pasión y el fuego (Méjean 2007: 88), y siguiendo con la idea de que una de las propiedades del fuego es su carácter 
purificador, se podría decir que la sangre derramada -y el sufrimiento padecido- por Vicente/Vera en su violación simboliza para Ledgard el punto y final del proceso de purgación del agresor de Norma (Vicente).

A pesar de la relevancia del Carnaval en el filme, también es significativo que, según el calendario litúrgico, los cuarenta días posteriores al Carnaval -la Cuaresma- se caractericen por la penitencia (la purificación) y la conversión en preparación para la Pascua, o la muerte-que, para Sócrates y Platón, era la purificación extrema- y el renacimiento. Asimismo, de acuerdo con las creencias antiguas sobre la alquimia, la transformación del metal imperfecto representa la mutación del hombre pecador que en la etapa del nigredo purifica su alma para convertirse en una entidad perfecta. Para Ledgard -otro pecador que acaba redimiéndose a través de su propia muerte al final del filme-Vicente ha de pagar por sus supuestos pecados mediante un proceso de purificación y mejora. Paradójicamente, dicho proceso de refinamiento consiste no solo en la tortura física y psicológica del paciente, además de la presunta expiración, o putrefacción, de su identidad y cuerpo anteriores, sino también en la simultánea asimilación y yuxtaposición de elementos diversos para confeccionar a un ser híbrido, aparentemente completo y perfecto. Tanto el palacete como el cuarto en el que está encerrada con llave la protagonista son espacios herméticos y claustrofóbicos que nos recuerdan que, a pesar de que reside en una mansión, también está presa mientras paga por sus propios pecados y los de Gal, y le va a ser casi imposible salir de allí. Según los símbolos de la alquimia, la imagen de la prisión -0 , en este caso, la del laboratorio-calabozo- representa el huevo filosofal o el alambique hermético, recipiente impenetrable dentro del cual ocurrían todas las transmutaciones que darían nacimiento a la piedra filosofal, o al hermafrodita. Efectivamente, es en su habitación donde Vicente/Vera hace penitencia y experimenta una transformación no solo física, sino también una más profunda y trascendental. Es la matriz en la que el/la protagonista se dedica a la meditación, al yoga y a sus propias faenas artísticas que le permiten no solo mantenerse cuerdo/a y estoico/a frente a una situación inaguantable, sino que también contribuyen a alimentar el conocimiento del/de la preso/a, ya que, de alguna forma, le ayudan a conocerse mejor a sí mismo/a. Gracias a su encierro, Vicente/Vera logra alcanzar el estado de trascendencia, ya que a raíz de ello descubre partes de sí mismo/a que antes no conocía, como su valentía y fortaleza. De igual manera, el mismo cuerpo y la nueva piel de Vicente/Vera también podrían equipararse al concepto del huevo filosofal mencionado con anterioridad, pues no solo representan una especie de cárcel en la que se siente preso/a, sino que también se realiza una metamorfosis física y existencial profunda debajo de esa piel.

\section{LA PERFECCIÓN DEL SUJETO HÍBRIDO E INDEFINIBLE}

Si volvemos a considerar el símbolo alquímico del uróboros, se ve que la serpiente no solo encarna el ciclo eterno de destrucción, creación, vida y muerte, sino también la asimilación y unión de las oposiciones binarias en un solo cuerpo, como el hermafrodita. En otras palabras, lo que se conoce en la alquimia como el 
rebis, el ser doble perfecto. ${ }^{8}$ Según Arturo Schwarz, para los alquimistas la figura del bisexual o hermafrodita -el rebis- a semejanza del oro, representa dentro de la filosofía hermética la perfección suprema y el ideal inalcanzable, ya que encarna al ser completo e inmortal que es, en consecuencia, divino (1980: 57), puesto que fue creado a imagen y semejanza de Dios. ${ }^{9}$ Gebelein sostiene, por su parte, que, ya que el hombre y la mujer son creados como seres separados, el "objetivo del trabajo del adepto es la recuperación de la unidad también en la sexualidad" o la unión de lo masculino y femenino en el andrógino o hermafrodita (2007: 38). De acuerdo con Jung, el proceso de individuación consiste en el conocimiento de que (co-)existe un sexo opuesto dentro del mismo individuo: el anima, o lo que Marie-Louise Von Franz identifica como el aspecto femenino de la psique masculina, y el animus, o el aspecto masculino de la psique femenina (1991: 177). Schwarz mantiene que esta autoconciencia, o aurea apprehensio, le permite al hermafrodita curar o soldar el cisma que lleva dentro (1980: 58). Mediante el proceso de individuación, el rebis incorpora la reconciliación o disolución de los opuestos en un solo ser. Como se puede ver, la individuación en el sentido alquímico conlleva la disolución de la dualidad masculina-femenina en conflicto consigo misma dentro de la personalidad íntegra del andrógino o del rebis. ${ }^{10}$

De manera análoga, después de la cirugía, Vicente renace como Vera, lo cual ahonda en la yuxtaposición, confusión o contienda de la identidad femenina con la masculina en un solo cuerpo, y representa un reto a las presuntas diferencias que separan al hombre de la mujer. Esta superposición no borra por completo su identidad anterior, sino que produce un personaje un tanto bigenérico y ambivalente, que está a caballo entre lo "femenino" y lo "masculino" y que, en consecuencia, es difícil de definir o de clasificar. A semejanza de las figuras monárquicas que aparecen en los manuscritos medievales sobre la alquimia, el/ la protagonista encarna lo andrógino, lo heterogéneo. Como ha señalado Barbara Zecchi en el nuevo cine queer de Almodóvar, el cineasta "pasa a un antiesencialismo que apunta a una más compleja desestabilización identitaria, que supera binarismos genéricos [...], posicionando la identidad sexual en contextos a menudo movedizos y ambivalentes" (Zecchi 2015: 35). Es más, para Marsha Kinder, quien considera las películas La flor de mi secreto (1995) y Hable con ella, existe una trans-subjetividad ("Reinventing" 2004: 253) que permite el flujo -o

${ }^{8}$ El alquimista mantiene que el último arcano, la tinctura, es como el rebis -la criatura que encarna lo masculino (azufre) y lo femenino (mercurio) a la vez- que transmuta el hierro o plomo en oro; tiñe o transforma el cuerpo, sacándole las partes dañinas, su rudeza y estado incompleto, así transformándolo en algo puro, noble e indestructible (Jacobi 1995: 148).

${ }^{9}$ Asimismo, como destaca Gebelein, según la tradición hermética, solo había un sexo al principio y "el Dios único primigenio posee en sí ambos sexos" (2007: 38).

10 Véase "'Gay Sensibility,' the Hermaphrodite, and Pedro Almodóvar's Films", de James Wyly, para entender mejor el concepto almodovariano del hombre y la mujer completos, además de la figura del hermafrodita en su obra, hasta 1999. Se ha de apuntar que Wiley, dos años más tarde, se pregunta en su estudio si el cineasta habría estudiado la alquimia, debido a la presencia de varios símbolos alquímicos dentro de su obra, pero, al final decide que es poco probable (2001: 236). Yo discrepo de esta valoración, pues Almodóvar recurre una y otra vez en su filmografía a los temas vinculados de la creación y la metamorfosis o la transmutación, existencial y corporal, además de lo intercambiables que son lo masculino y lo femenino, como demuestra Méjean (2007: 56). 
la confusión e intercambiabilidad- entre el Yo y el Otro. Centrándonos una vez más en La piel que habito, en su proceso transformativo la otredad femenina y el sujeto masculino convergen hasta tal punto que el "Yo" (Vicente) queda transformado para siempre en el "Otro" (Vera/Gal), haciendo casi imposible precisar dónde termina Vicente y dónde empieza Vera/Gal. Como señala Zecchi, cuando Ledgard se acuesta por primera vez con Vera, la cámara se detiene en la cara de esta, que está tumbada y soñando, que "a su vez, por un fundido, se encadena con la de Vicente" (2015: 49). Esta ofuscación de los límites existenciales se pone de manifiesto una vez más cuando Zeca distingue la imagen de Vera en la pantalla de seguridad de la cocina y la confunde con Gal, o incluso cuando Norma confunde a su padre con su violador (Vicente).

Es más, debido a que la piel de Vera está hecha de las células de cerdo y varias partes de su cuerpo están compuestas por una combinación de sustancias sintéticas, Almodóvar hace que reflexionemos sobre los límites existenciales, tanto sobre lo que significa ser "hombre" o "mujer" como sobre la diferencia entre lo puro y lo contaminado, o simplemente lo que define al ser humano. Debido a tales interrogantes ontológicos e identificaciones erróneas, cabe indagar en el carácter post-humano de la protagonista, ya que esta representa el fruto de nuevas tecnologías, específicamente de la ingeniería genética humana. Inspirado tal vez por los desarrollos biotécnicos que permiten el traslado de una materia genética de una especie a otra, Almodóvar ofusca los límites entre las diferentes especies biológicas y acentúa la proximidad del ser humano no solo con los demás animales, sino incluso con las máquinas. Como el cyborg de Haraway o el mismo monstruo de Frankenstein -ejemplos de la fusión de lo orgánico y lo cibernético- Vera está compuesta tanto de partes humanas como de fragmentos sintéticos y, por ende, destaca como un cuerpo e identidad transhumanos. Como prototipo del sujeto postmoderno por excelencia, Vera traspasa y desestabiliza los límites existenciales, ya que no es ni mujer ni hombre, y ni siquiera un ser humano íntegro, sino una entidad paradójica e indefinible, similar al pastiche. Es evidente que Vera es una figura dividida y ambigua, la cual, a semejanza del cyborg, el rebis de la alquimia o de la figura del transexual, se define por la (con) fusión de los límites existenciales. Es decir, Vera representa la síntesis y fluidez del Yo y del Otro y lo masculino y femenino, lo cual pone de manifiesto el hecho de que en el hermafrodita lo ajeno se vuelve propio y vice versa. Asimismo, y desde el punto de vista de la psicología, Vera se sigue identificando con el género masculino, mientras posee el sexo anatómico femenino, enfatizando una vez más la diferenciación que en El segundo sexo (1949) de Beauvoir destaca entre los conceptos de sexo y género, a la vez que los mezcla e invierte.

Hemos visto que en muchos de los filmes anteriores del cineasta manchego la figura del transexual acaba ocupando un lugar privilegiado, el del escenario real tanto como el del figurado, lo cual resalta el fuerte vínculo que existe entre el género y la mise-en-scène. Según Paul Julian Smith, es improbable que a Almodóvar le interesen los transexuales en sí, pero lo que sí le interesa es enfatizar la distinción entre el artificio y la verdad que ha oprimido tanto a los disidentes sexuales (2000: 87). Vera, que antes era Vicente, ahora encarna no solo el 
arquetipo patriarcal de la belleza femenina -con su piel luminosa, sus senos suaves y "naturales" y su estado de subordinación- sino que también representa el fruto de la creación, la reproducción y el proceso alquímicos, ya que personifica un ideal concebido, fabricado y perfeccionado por su creador. El nuevo género que personifica Vicente/Vera es una farsa o, como propone Butler en Gender Trouble (1990), un constructo social que normalmente oculta sus orígenes para aparentar ser más auténtico, lo cual también se podría decir del oro alquímico. Por otra parte, al igual que los conceptos de identidad y género, en Bodies That Matter (1993), Butler afirma que el cuerpo, sus actos, gestos y realizaciones son "performativos en el sentido de que la esencia o la identidad que pretenden expresar son inventos fabricados y mantenidos mediante signos corpóreos" (1993: 167, énfasis de la versión original) que constituyen la ilusión de un ser que obedece y reproduce las normas tradicionales de su género. Por extensión, si se acepta que el género y la sexualidad gravitan en una construcción o performance deliberados y estratégicos, esto requiere la presencia de un espectador o público colectivo al que se le tiene que convencer. Al mismo tiempo, requiere que el mismo actor o actriz se haya convencido/a de su propia autenticidad para que la interpretación tenga éxito. En sus estudios sobre la obra almodovariana, Carla Marcantonio señala que los personajes transexuales suelen estar vinculados por la crítica con el carácter performativo de la identidad (2008: 163). Es más, Marcantonio subraya la duplicidad de la figura de la femme fatale en Tacones lejanos (1991) y La mala educación, declarando que es una mujer de intenciones sospechosas, con un pasado inexistente, que nunca es lo que aparenta ser (2008: 164), lo cual recuerda el caso de Vicente/Vera. Los temas interrelacionados del mise-en-scène y la transformación física y existencial-encarnadas por la figura del travesti o, en este caso, por el transexual- se pueden vincular, de manera simbólica, a la mutación y el proceso alquímicos.

En el fondo, el género teatral se asemeja al proceso alquímico, puesto que los dos se fundamentan tanto en la ilusión (Gebelein 2007: 197) como en la reproducción y en el rito de la transformación. De acuerdo con Antonin Artaud, "[h]ay entre el principio del teatro y el de la alquimia una misteriosa identidad de esencia" que radica en el proceso de la creación y en la operación teatral de la fabricación del oro (1932: 62). Asimismo, al convertirse en (el) o/Otro, mediante la imitación o representación, el actor/transexual también es un alquimista más. De esta forma, manipula a su espectador y ofusca los opuestos de la verdad y la mimesis, e incluso del "Yo" y el "Otro", haciendo que el espectador se identifique con él y obligándole a compartir su catarsis. ${ }^{11}$ Al igual que el alquimista, el dramaturgo/artista o intérprete trata de emprender un tipo de creación y transformación, una conversión de la materia básica en oro imaginario (es decir, la metá-

\footnotetext{
11 John Granger asevera que el concepto alquímico de la purificación por medio de la identificación o correspondencia con un objeto y sus transformaciones encaja perfectamente con el propósito del teatro. Propone que William Shakespeare y Benjamin Johnson, entre otros, incorporaban ciertos temas e imágenes asociados con la alquimia porque comprendían que la transformación humana que ocurre en una obra teatral se asemeja al proceso alquímico. Señala que, como espectadores o lectores, al identificarnos con los personajes, nosotros también nos acabamos transformando (2008: 30).
} 
fora de la imitación perfecta). Asimismo, en The Limits of Illusion, al citar a Ortega y Gasset, Anthony Cascardi declara que "the theatre is a visible metaphor, a locus of transformation" (1984: 96) y, más adelante, cita al mismo Artaud, el cual equipara el símbolo alquímico y el arte dramático a un espejismo (102) que acaba seduciendo y engañando al espectador. Así, a semejanza de la alquimia, dos de los objetivos del performance, tanto de género como de la puesta en escena, son forjar una identidad concreta y creíble para crear la ilusión de la realidad.

Haciéndome eco, una vez más, de los elementos carnavalescos y teatrales que aparecen en el filme, creo oportuno destacar que varios de los personajes llevan distintas máscaras -extensiones de la misma epidermis- en diversos momentos de la película, sea para ocultar el rostro y salvaguardar el anonimato, sea para protegerse la piel. ${ }^{12}$ La misma piel sintética de Vera le acaba sirviendo de atuendo y disfraz, pues emplea este escudo protector para aparentar que acepta su nueva piel e identidad femenina y, como resultado, engañar a Ledgard, ocultándole su verdad (o identidad) interior. Mientras que el propósito principal del antifaz y el disfraz, de forma paralela al proceso alquímico, es encubrir y transformar la identidad o la esencia de alguien o de alguna sustancia, también se puede usar para re-inventarse, como en los casos particulares de Ledgard y Zeca, los cuales se tapan la cara para no ser reconocidos ni por las autoridades ni por sus futuras víctimas. A diferencia de su carcelero y violador, la máscara blanca tanto como el body que lleva Vera no tapan un rostro, cuerpo o identidad "propios", sino que esconden otra identidad tan impuesta y artificial como la misma piel que la envuelve. ${ }^{13} \mathrm{El}$ mismo nombre que Ledgard le proporciona a su magnum opus, Vera, insinúa que todo aquello que se ha fabricado o adulterado es aún más auténtico y noble que la versión original. ${ }^{14} \mathrm{Al}$ ser un simulacro más perfecto que su modelo Gal, Almodóvar resalta la idea de que la identidad y el

\footnotetext{
12 Como destaca Gavela-Ramos en su análisis del largometraje, Almodóvar revela un mundo carnavalizado en el que todo se invierte y el agresor se convierte en el agredido (2013: 129). Vicente, el violador de Norma, se ha transformado en el Otro (o en la Otra), en el cuerpo extraño y femenino, cuyas funciones principales son satisfacer el placer sexual y ser observada, deseada y dominada por el sujeto masculino. De manera paradójica, al ser transgredida por el hombre-tigre, Vera/Vicente es obligada/o a asumir el papel -y la piel- de la "virgen" violada y el mismo "violador" acaba transformándose en y simpatizando con la víctima de su propio y presunto crimen.

13 Esta máscara fálica manifiesta el carácter andrógino o hermafrodita de Vicente/Vera, ya que exhibe cualidades y símbolos que se podrían clasificar de masculinos tanto como de femeninos. La máscara, como la piel -que también sirve de antifaz- encubre y protege lo "femenino" mientras que el contorno de la nariz y la boca de la paciente evoca patentemente la figura fálica. Cuando el doctor le insta a su paciente a que aprenda a respirar por "ese agujero" (refiriéndose a su nuevo orificio vaginal, aunque el perfil del falo que le rodea la nariz y la boca también lo podría ser), ya que su vida depende de ello, lo dice de manera figurativa y literal, pues Vicente/Vera tiene que encarnar e improvisar tanto su feminidad impuesta como su integridad biológica y masculina para sobrevivir.

14 Esta postulación corrobora lo que Steve Marsh ha detallado sobre la figura de la Agrado en Todo sobre mi madre y lo que Smith indica sobre Kika en el filme homónimo. Ambos críticos sostienen que el/la travesti (o transexual) es más auténtico/a como travesti que su identidad anterior al cambio. En esta misma línea, es curioso apuntar que, en la antigua alquimia china, existía la teoría de que el oro falso era superior al oro auténtico, puesto que poseía una esencia superior y más diversa que la del oro natural (Cooper 2016: 65).
} 
género de una persona son, por definición, artificiales, maleables y performativos, y que la autenticidad y la perfección son ideales paradójicos y subjetivos.

En el prólogo de Gender Trouble, Butler observa que la imitación de lo femenino insinúa que el género es un tipo de reproducción constante que pasa por lo real y lo auténtico (1990: xxxi). Asimismo, tal y como postula Mark Allinson, la obra cinematográfica almodovariana está repleta de improvisaciones, o de "'plays' of femininity", y de hombres que procuran pasar por mujeres "naturales" (2001: 149). Como he señalado anteriormente, Vera ha sido moldeada precisamente para que aparente ser una mujer auténtica. A pesar de que a Vera se la ha transformado contra su voluntad, cerca del final del filme ella parece asumir un papel más activo en su propia evolución física y existencial, disimulando que acepta y desea encarnar más convincentemente, su nueva piel e identidad. Por tanto, la protagonista, o el fruto alquímico, acaba comportándose como una alquimista más, ya que pone el punto y final a su propia transformación..$^{15}$ Vera sabe que para sobrevivir necesita adaptarse a su nuevo papel y mentir, o disfrazar su ser interior para convertirse en la mujer perfecta que Ledgard quiere que personifique. Con tal de que su plan salga bien, hace falta que Vera finja no solo estar enamorada de su padre creador, sino que también disimule aceptar su papel de mujer "heterosexual". En realidad, Vera ya está acostumbrada a participar en las puestas en escena, debido a las cámaras que siempre la vigilan en su cuarto, y sabe muy bien encarnar e interpretar el nuevo género que se ha impuesto. El mismo día en que mata a su carcelero y se libera de él, Vera le anuncia que se pondrá los tacones para salir de compras e "ir practicando" para encarnar mejor su estereotipada feminidad y parecer más auténtica. Los zapatos, los vestidos nuevos y el maquillaje que antes había rechazado le sirven ahora de disfraz para construirse una identidad además de su propio magnum opus: su puesta en escena que servirá para engañar a su padre-creador. Para convertirse en mujer, de

\footnotetext{
${ }^{15}$ Cabe señalar que, a semejanza de Ledgard, Vicente/Vera también está acostumbrado/a a emplear las manos para forjar cuerpos y reproducir obras de arte, solo que este/esta trabaja con los tejidos de ropa que tiene a su disposición tanto en la boutique de su madre como en su cuartocelda de El Cigarral. En su trabajo de costurero, Vicente se dedica a elaborar y alterar vestidos para mujeres -o maniquíes del escaparate- $y$, de forma paralela, Ledgard realiza una nueva piel que cubrirá a su propio maniquí humano, Vicente/Vera. Como en la escena anterior, en la que vemos al cirujano colocando meticulosamente los tejidos de piel sintética en el maniquí y después en el cuerpo de Vera, vemos más tarde cómo esta, de forma análoga, ubica con esmero los retales de tela desgarrados de las prendas que cuelgan de su armario en sus muñecas de trapo, que guardan semejanza con las obras tituladas Cell XIV (Portrait) (2000) y "No Exit" (1989) de la escultora franco-estadounidense Louise Bourgeois. Como señala María Teresa Cabello Ruiz, estas muñecas recuerdan a las personas de rostros vendados por "una lesión, quemadura o proceso quirúrgico, semejantes a Christiane Génnesier, Vera, o la esposa del doctor Ledgard" (2014: 42). Luego, en una tercera escena, se ve a Ledgard en el patio de su casa podando un bonsái y ligándole las ramas con fragmentos de cuerda. El arte del bonsái consiste en cultivar árboles con el objetivo de reducir su tamaño mediante una serie de técnicas diseñadas para manipular y modelar su forma, de manera contraria a sus patrones naturales, como la poda, el alambrado, la alimentación y el trasplante. No obstante, están modelados para imitar otros árboles más grandes que aparecen en la naturaleza para, así, darles la forma deseada. Para los monjes taoístas chinos, el árbol representaba lo eterno, y servía de puente entre lo humano y lo divino. Estas escenas interrelacionadas de la película reproducen el mismo proceso al que es sometido/a Vicente/Vera y hacen hincapié en el afán humano no solo de crear, sino también de domar y transformar la naturaleza para obligarla a satisfacer nuestros ideales de belleza y nuestros caprichos más perversos.
} 
acuerdo con las afirmaciones de Butler, la protagonista tiene que pasar por un proceso teatral de "appropriating, interpreting, and reinterpreting" (hacer suyos, interpretar y volver a interpretar) distintos modelos culturales ("Sex and Gender" 1986: 36) del género que desea reproducir. Es más, aunque por fuera parezca ser mujer, tiene que convencer a su creador de que ella misma cree serlo.

Cuando Vicente/Vera simula aceptar su feminidad ante Ledgard parece conciliar su ser interno (su esencia o género) con su ser externo (su sexo), no obstante, dicha armonía no es más que una quimera diseñada para engañar a su carcelero/espectador. Al volver al caserón, Vera interrumpe una discusión entre Ledgard y su colega, ya que este acaba de descubrir el crimen del cirujano y piensa chantajearlo. Ante el asombro de sus espectadores, Vera parece querer proteger a su creador-victimario y le asegura al colega que el médico no la secuestró ni le aplicó la transgénesis, sino que ella "siempre [fue] una mujer", haciendo que sospechemos que sufre del síndrome de Estocolmo. Mediante este discurso tan contundente, junto con su promesa la noche anterior de que nunca abandonará al cirujano, Vera logra convencer a su espectador demasiado crédulo (Ledgard) no solo de sus intenciones benévolas y de su "veracidad", sino también de su capacidad de transformarse y de olvidarse de una identidad anterior que ahora sugiere que era falsa e indeseada. Así, la segunda piel que asume, y que se ve obligada a aceptar por la fuerza, acaba sirviéndole también de antifaz, el cual la protege de su carcelero, permitiéndole también engañar no solo a Ledgard, sino incluso al espectador de cine. En una de las últimas escenas de la película, cuando Ledgard le pide a Marilia que lleve a Vera al centro para comprarle ropa nueva, el ama de llaves le reprocha el confiar demasiado en las mujeres que lo rodean, insinuando que todas (incluso ella, su propia madre) le han engañado sin que él se diera cuenta. Marilia insinúa que, a diferencia de su hijo, ella nunca se había fiado de Gal y que tampoco se fía ahora de Vera, de quien está convencida que es una farsante más. Antes de matar a su amo-creador y huir de El Cigarral, un Ledgard visiblemente aturdido le recuerda que le prometió que nunca lo abandonaría, a lo que su homúnculo postmoderno, Vera, le contesta de forma brusca y displicente, "te mentí". Lo cual discrepa irónicamente del significado de su nombre, a la vez que resalta no solo su carácter contradictorio, sino también lo viscosas que son la verdad y la mentira. ${ }^{16}$ De manera paradójica, el escrupuloso y despiadado cirujano-alquimista esconde en su interior a un niño ingenuo, incapaz de diferenciar lo falso de lo verídico.

Es evidente que el contexto existencial de Vicente/Vera es el inverso del de tantos personajes almodovarianos transexuales que deciden cambiar de sexo para mejor encarnar su visión de la autenticidad, y esto sirve para destacar la impresión de ilegitimidad o fraude que experimentan los que no se identifican con su cuerpo o género impuesto. Por ejemplo, en Todo sobre mi madre, la Agrado se hace una serie de intervenciones quirúrgicas precisamente porque la única manera de sentirse más "auténtica" radica en que su identidad (la imagen que ella

\footnotetext{
16 Francisco Zurian nos recuerda que el nombre de Vera proviene de veritas, lo cual Zurian señala que es una mentira, ya que al poseer una piel que no es humana, Vera encarna la falsedad (2013: 268).
} 
tiene de sí misma) y su cuerpo por fin se pongan de acuerdo. Además, a muchos transexuales les parece que han estado viviendo atrapados en el cuerpo o la piel de(l) o/Otro. Cabe reconocer que, a diferencia de muchas de sus antecesoras almodovarianas, Vera no emprende los cambios fisiológicos a los que ha sido sometida -sino que ha sido su carcelero el que se los ha hecho- lo cual equipara las acciones de Ledgard a otra violación más para la víctima. Almodóvar parece subrayar aquí una analogía muy importante con la transexualidad dirigida a su público, con el fin de cultivar en él la compasión por los que sienten que se les ha asignado el sexo equivocado al nacer. La discordancia que siente Vicente/Vera entre su identidad impuesta femenina y su sexo biológico e identidad masculinos es la que impulsa al transexual a emprender el proceso de transformación para encarnar lo que para él o ella representa lo más afín a la autenticidad. Como cualquiera que no se siente cómodo en su propia piel, el nuevo cuerpo e identidad de la protagonista funcionan como una cárcel o cadena perpetua de las que no puede huir.

La incongruencia entre lo corpóreo y lo emocional-psicológico, o el repudio del sexo impuesto, se detecta en varios momentos del filme, particularmente en la escena en que Vera desgarra los vestidos que están colgados en su armario. Dichos atuendos representan la asignación de una identidad y género indeseados, y los pedazos de ropa tirados por el suelo de su habitación son el resultado de su rechazo de ese castigo. Durante la mayor parte de la película, Vicente/Vera se siente como un/a foráneo/a obligado/a a habitar un cuerpocasa-cárcel que no le corresponde. No obstante, como insiste la instructora de yoga (que aparece en el televisor de su dormitorio) a sus televidentes, hay que hallar un lugar de refugio; un lugar que esté en su interior y al que nadie pueda acceder o destruir, advirtiéndoles que no hay que confundir la forma con el fondo. Almodóvar parece insertar aquí la tesis principal de su largometraje, la cual se vincula a la cuestión de la identidad analizada en este estudio. El fondo de Vicente/Vera es lo que él/ella mismo/a considera que representa su ser más auténtico, mientras que la forma -la piel, el nombre, incluso el órgano reproductivo femenino- simboliza lo superficial y lo falso, pues no encaja con su visión de sí mismo/a. Al final de la película, cuando Vera, envuelta en un vestido ajustado y aflorado, vuelve a la boutique de su madre y le anuncia, "Soy Vicente", parece haber aceptado, hasta cierto punto, la incompatibilidad de su identidad (su género) y su nuevo físico (su sexo). $O$, como ha señalado Paul Julian Smith en su análisis del personaje de Antonio/Tina en La ley del deseo, parece tratar de crear la sensación de una identidad singular y continua (2000: 85). Sin embargo, la incongruencia de lo que se ve y lo que se escucha les resulta problemático e incoherente tanto al espectador como a la madre del/de la protagonista, pues parece casi imposible que no se enrede la forma, o la piel, con el fondo del personaje. No obstante, estas últimas palabras de Vicente/Vera también representan un desafío en contra de los castigos o deseos de Ledgard; es decir, indican un rechazo a su sexo asignado, a la vez que señalan su autonomía y aceptación de su heterogeneidad existencial. Por una parte, la identidad verdadera y original de Vicente (nombre que significa vencedor, conquistador o seductor) vence a la 
impuesta; por otra, el cambio físico le permite a Vicente/Vera seducir a Cristina, la ayudante lesbiana de su madre que, antes de su transformación, ignoraba sus insinuaciones por el hecho de que era hombre. Al insistir en que su "verdadero" nombre y esencia siguen siendo los mismos de antes, Vicente/Vera nos recuerda que la transformación física a la que ha sido sometido/a no determina, necesariamente, la esencia ni la autenticidad de su "Yo" interior. El reencuentro con su madre seis años después de su desaparición hace que Vicente/Vera resucite de nuevo, de forma simbólica, después de un largo período de reclusión. Como la cigarra, habita una nueva piel y escapa de su mundo subterráneo para seguir adelante con la próxima etapa de su vida.

\section{CONCLUSIÓN}

La figura del transexual, tan emblemática en el cine del director manchego, no solo encarna las declaraciones de Butler acerca del carácter performativo del género, sino también el modelo y proceso alquímicos, poniendo en tela de juicio nuestras nociones acerca de la autenticidad y la identidad. Aparte de decir que el género es la estilización repetida del cuerpo, Butler pinta el género como si fuera el fruto de un proceso alquímico. Sostiene que es "a set of repeated acts within a highly rigid regulatory frame that congeal over time to produce the appearance of substance, of a natural sort of being" (Gender Trouble 1990: 33; el énfasis es mío). De esta forma, la citada investigadora alude a la elaboración tanto del género como de la identidad, mediante una serie de actos performativos y miméticos, cuyo objetivo es simular la autenticidad. El ejemplo de la alquimia nos recuerda que "no es oro todo lo que reluce, por lo menos, no oro puro". De manera análoga, Vera no es una mujer "pura", sino un hombre trocado, o el mero espejismo o reproducción de la mujer -y de la piel- perfecta. Aunque Vicente, junto con su piel sintética, sus senos verosímiles y su nuevo orificio, no parece ser el mismo de antes, debido a una serie de pérdidas y cambios profundos, al final de la película, como asevera Vera, vuelve a ser -o nunca ha dejado de serVicente. En realidad, no es ni hombre ni mujer, y, como he señalado a lo largo de este estudio, Vicente/Vera representa al sujeto alquímico perfecto del hermafrodita, o a un tercer género, un híbrido de lo masculino y femenino, el símbolo de la fluidez y la trascendencia de las rígidas dicotomías genéricas establecidas. Es más, mediante una consideración de los elementos alquímicos presentes en la obra, se percibe que Almodóvar propone que la identidad, como el género, es un concepto indeterminado y a veces engañoso, que todos vamos improvisando, interpretando y perfeccionando a lo largo de la vida, mientras que los límites entre lo falso y lo auténtico, lo femenino y lo masculino, y lo humano y lo no-humano son extremadamente difusos. Como un alquimista obsesionado con la transmutación y la perfección de su obra, el cineasta manchego efectúa su última transformación: la del espectador, quien, a medida que va avanzando la trama, llega a un punto de gnosis, de autoconciencia agudizada y de crecimiento personal, análogo al de Vicente/Vera. La revelación sobre la "verdadera" identidad y los orígenes de Vera -la cual se produce hacia mitad del largometraje- no 
solo inquieta y enseña al espectador que las apariencias a veces engañan, sino que este descubrimiento, junto con el caso insólito de Vicente/Vera, también lo conmueve y estimula a que se ponga en la piel compleja y paradójica del Otro.

\section{OBRAS CITADAS}

Aldana Reyes, Xavier (2013): "Skin Deep? Surgical Horror and the Impossibility of Becoming Woman in Almodóvar's The Skin I Live In", Bulletin of Hispanic Studies, n.0 90, pp. 819-834.

Allinson, Mark (2001): A Spanish Labyrinth: The Films of Pedro Almodóvar. Londres, I. B.

Tauris \& Co. Ltd.

Almodóvar, Pedro (dir.) (2011): La piel que habito. España, El Deseo.

— (2011): La piel que habito: Información/Sinopsis, <http://www.lapielquehabito.com/ info.php> (última visita: 12.4.2014).

_ (dir.) (2004): La mala educación. España, El Deseo.

— (dir.) (2002): Hable con ella. España, El Deseo.

— (dir.) (1999): Todo sobre mi madre. España, El Deseo.

— (dir.) (1995): La flor de mi secreto. España, El Deseo.

— (dir.) (1993): Kika. España, El Deseo.

— (dir.) (1991): Tacones lejanos. España, El Deseo.

— (dir.) (1990): ¡Átame! España, El Deseo.

_ (dir.) (1982): Laberinto de pasiones. España, Musidora.

Artaud, Antonin (1932): "El teatro alquímico". En Biblioteca virtual Miguel de Cervantes (Cervantes virtual), <http://www.cervantesvirtual.com/obravisor/sur2/html/027 eb2662b2-11df-acc7002185ce6064_11.html> (última visita: 15.5.2014).

Azara, Pedro (1995): La imagen y el olvido: el arte como engaño en la filosofía de Platón. Madrid, Siruela.

Ballesteros, Isolina (2001): Cine (ins)urgente: textos filmicos y contextos culturales de la España postfranquista. Madrid, Fundamentos.

Beauvoir, Simone de (2005): El segundo sexo. Madrid, Cátedra.

Bonatto, Adriana Virginia (2017): "Entre lo propio y lo ajeno: modulaciones identitarias fronterizas en Pedro Almodóvar, Eduardo Mendicutti y Luis Antonio de Villena", Revista Estudios Feministas, pp. 1473-1487.

Bourgeois, Louise (2000): Cell XIV (Portrait). Londres, Tate Britain.

_ (1989): "No Exit". Washington, D.C., National Gallery of Art.

Butler, Judith (2011): Bodies That Matter: On the Discursive Limits of "Sex". Londres, Taylor \& Francis Group.

- (1990): Gender Trouble: Feminism and the Subversion of Identity. Londres, Routledge.

_ (1986): "Sex and Gender in Simone de Beauvoir's Second Sex", Yale French Studies, n. 72, pp. 35-49.

Cabello Ruiz, María Teresa (2014): "Intertextualidad en La piel que habito: Louise Bourgeois según Pedro Almodóvar", Sesión no numerada: Revista de letras y ficción audiovisual, n. ${ }^{\circ}$, pp. 34-46. 
Cascardi, Anthony J. (1984): The Limits of Illusion: A Critical Study of Calderón. Nueva York, Cambridge University Press.

Cooper, Jean (2016): Chinese Alchemy: Taoism, the Power of Gold, and the Quest for Immortality. Newburyport, Massachussetts, Weiser Books.

Dixon, Laurinda (1981): Alchemical Imagery in Bosch's Garden of Delights. Ann Arbor, UMI Research Press.

Franju, Georges (1959): Les yeux sans visage. París, Champs-Élysées Productions.

Gavela-Ramos, Yvonne (2013): "La piel que habita el cine de Almodóvar: la autenticidad del artificio", La Nueva Literatura Hispánica, n. ${ }^{0}$ 17, pp. 113-138.

Gebelein, Helmut (2007): Secretos de la alquimia. Trad. Elisenda Solergibert. Barcelona, Ediciones Robinbook.

Granger, John (2008): How Harry Cast His Spell: The Meaning Behind the Mania for J.K. Rowling's Bestselling Books. Carol Stream, Illinois, Tyndale House Publishers, Inc.

Jacobi, Jolande (1995): Paracelsus: Selected Writings. Princeton, Princeton University Press. Jonquet, Thierry (1999): Mygale. París, Gallimard.

Jung, Carl Gustav (1953). Psychology and Alchemy. Londres, Routledge \& Kegan Paul Ltd.

Kinder, Marsha (2009): "All About the Brothers Retroseriality in Almodóvar's Cinema". En En Brad Epps y Despina Kakoudaki (eds.): All About Almodóvar: A Passion for Cinema. Minneapolis, University of Minnesota Press, pp. 267-294.

- (2004): "Reinventing the Motherland: Almodóvar's Brain-Dead Trilogy", Journal of Spanish Cultural Studies, pp. 245-260.

Knapp, Bettina L. (1980): Theatre and Alchemy. Detroit, Wayne State University Press.

Lacan, Jacques (1958): "La signification du phallus". En: Écrits. Nueva York, Norton \& Company, p. 685.

_ (1949): "Le Stade du miroir comme formateur de la fonction du Je: telle qu'elle nous est révelée dans l'expérience psychanalytique", Revue française de psychanalyse, pp. 449-455.

Lang, Fritz (dir.) (1927): Metropolis. Alemania, UFA.

Marañón Bertrán de Lis, Gregorio (2015): Memorias del Cigarral: 1552-2015. Barcelona, Ediciones El Viso.

Marcantonio, Carla (2008): "The Transvestite Figure and Film Noir: Pedro Almodóvar's Transnational Imaginary". En Vicent Ortega y Jay Beck (eds.): Contemporary Spanish Cinema and Genre. Manchester, Manchester University Press, pp. 157-178.

Marsh, Steven (2009): "Missing a Beat: Syncopated Rhythms and Subterranean Subjects in the Spectral Economy of Volver". En Brad Epps y Despina Kakoudaki (eds.): All About Almodóvar: A Passion for Cinema. Minneapolis, University of Minnesota Press.

Martínez-Expósito, Alfredo (2004): Escrituras torcidas: Ensayos de crítica "queer". Barcelona, Laertes.

Méjean, Jean-Max (2007): Pedro Almodóvar. Barcelona, Robinbook.

Newman, William R. (2005): Promethean Ambitions: Alchemy and the Quest to Perfect Nature. Chicago, University of Chicago Press.

Rodríguez Ocaña, Esteban; Esteva de Sagrera, Juan (1991): La química sagrada: de la alquimia a la química en el siglo XVII. Madrid, Akal. 
Schwartz-Salant, Nathan (2003): The Mystery of Human Relationship: Alchemy and the Transformation of the Self. Londres, Routledge.

Schwarz, Arturo (1980): "Alchemy, Androgyny and Visual Artists", Leonardo, vol. 13, n. ${ }^{0}$ 1, pp. 57-62.

Smith, Paul Julian (2000): Desire Unlimited: The Cinema of Pedro Almodóvar. Londres, Verso. Strauss, Frédéric (2000): Conversations avec Pedro Almodóvar. París, Cahiers du Cinéma.

Von Franz, Marie-Louise (1991): Alquimia: Introducción al simbolismo. Barcelona, Luciérnaga.

Warlick, M.E. (2003): Las piedras de la alquimia. Londres, Edaf.

Wyly, James (2001): "'Gay Sensibility', the Hermaphrodite, and Pedro Almodóvar's Films". En Christopher Hauke y lan Alister (eds.): Jung and Film: Post Jungian Takes on the Moving Image. East Sussex, Brunner-Routledge, pp. 226-242.

Zecchi, Barbara (2015): "El cine de Pedro Almodóvar: De óptico a háptico, de gay a 'new queer'", Área Abierta, vol. 15, n. ${ }^{\circ} 1$, pp. 31-52.

Zurian, Francisco A. (2013): "Creative Beginnings in Almodóvar's Work". En Marvin D'Lugo y Kathleen M. Vernon (eds.): A Companion to Pedro Almodóvar. West Sussex, Wiley Blackwell, pp. 39-57. 